\title{
Can Universities be a Gleam of Hope During COVID-19? Entrepreneurial Intentions Approach for Academia in Pakistan
}

\author{
Guohao $\mathrm{Li}^{1}$, Sabeeh Pervaiz ${ }^{1 *}$ and Qi He${ }^{2}$ \\ ${ }^{1}$ School of Management, Jiangsu University, Zhenjiang, China, ${ }^{2}$ School of Finance and Economics, Jiangsu University, Zhenjiang, \\ China
}

The COVID-19 epidemic has wreaked havoc on the economics of several countries. Downsizing, job shortages, and unemployment are among the significant effects. The markets are supported by the need to train and educate our youth to be job producers rather than job seekers. This study sought to investigate the role of universities in the formation of students' attitudes toward entrepreneurship by analyzing the influence of locus of control, extracurricular activities, and curriculum on entrepreneurial intention among Pakistani university students. This study collected data from 536 students across 15 universities in Pakistan through a weblink questionnaire. SPSS and AMOS were used to test the theoretical model. Results confirmed that locus of control positively affects entrepreneurial intentions and is the strongest predictor among the other two variables. Extracurricular activities positively affect entrepreneurial intentions, and curriculum is also positively affecting entrepreneurial intentions. This study concluded that entrepreneurial education and acquaintance are essential in bringing entrepreneurial intentions among students. Locus of control is found to be the most substantial element in developing entrepreneurial intentions among students. Educational institutions can play a critical role by proactively contributing through their efficient and proficient curricula, professional and experienced teachers, and locus of control by combining curricular and co-curricular activities.

Keywords: locus of control, university curriculum, extracurricular activities, entrepreneurial intentions, theory of planned behaviors, COVID-19

\section{INTRODUCTION}

The global COVID-19 epidemic has raised numerous issues, impacting millions to billions of individuals in the sanitary and health sectors. On the other hand, organizations have had to deal with the new realities of the global economic slump (Dias et al., 2020). Due to immersing economic pressure on the organizations at this particular time, companies were forced to downsize their employees, and many lost their jobs (Loayza and Pennings, 2020; Lord, 2020). COVID-19 has left poor nations with little choice but to work with a smaller workforce and less resources. It has also increased the pressure on wealthy nations to control inflows (Hopman et al., 2020). According to recent research, young people suffer the most, not just in terms of lost jobs but also in terms of time spent gaining expertize (Hopman et al., 2020). Pakistan, like many other emerging countries, has 
recorded a large number of job terminations. With this figure anticipated to climb in the following months, young people's dread of being laid off has skyrocketed (Waris et al., 2020).

World economies are contracting in the modern period as a consequence of resource scarcity caused by COVID-19, which has resulted in significant unemployment rates and income inequities. Instead of seeking work, it is necessary to generate jobs for others (Crayne, 2020). As a result, sustaining the world's ever-growing population, the demand for better jobs, and better managing the economic impacts of COVID-19. The phrase entrepreneurship refers to forming a mindset in the pursuit of financial gain, job possibilities, and the best use of existing resources to achieve maximum results (Long, 1983). Entrepreneurship in SMEs (small and medium-sized enterprises) captured the attention during this challenging time by providing few employment opportunities. Simultaneously, several recruited a team of the same minds or family members to start a small business (Akpan et al., 2020; Fitriasari, 2020). Those who had entrepreneurial solid understanding and education were able to make a living. As a result, educating the kids about entrepreneurship can aid in the future fight against pandemics. It's only feasible if young people have entrepreneurial instincts and expertize. Students with greater experience, drive, and abilities will be more confident in their ability to overcome obstacles (Salamzadeh et al., 2014).

Universities are seen to be the formative force in any culture. They prepare students to deal with any unknown scenarios that may arise in the future. These institutions can foster entrepreneurial mindsets through their practical curricula, competent and experienced staff, locus of authority, and cocurricular activities. Higher educational establishments (universities) can play a critical role in developing entrepreneurial ambitions among the youth. Graduates from such colleges are the catalysts for economic growth, since they can make entrepreneurial decisions (Saeed et al., 2015). Studies strongly reflect the effects of entrepreneurial intentions from a very early stage, which later leads to the gestation phase of business development, compared to the people who lack intuition are reluctant to do business (Nabi et al., 2018; Meoli et al., 2020). The idea of exposure to entrepreneurship education in bringing entrepreneurial intentions tended to opt for their own business compared to the people who had little or no entrepreneurial education (Farsi et al., 2012; Wannamakok and Liang, 2019).

Studies have been extensively conducted in developed countries to measure universities' importance in students' entrepreneurial attitude development (Guerrero et al., 2016; Ozaralli and Rivenburgh, 2016; Zollo et al., 2017). Due to cultural restrictions and insufficient resources, the significance and value of entrepreneurial exposure and educational variables have been largely overlooked in underdeveloped nations. The administration in many developing nations is similarly skewed in favor of the country's wealthy elite. As a result, the newcomer has very limited ground on which to build their firm. As a result, pandemics have a greater impact on the educational ecology of underdeveloped nations (Kawamorita et al., 2020). Furthermore, there should be no gender discrimination and equal chances.
Female entrepreneurs were formerly discouraged in Pakistan, but this is rapidly changing (Yousfani et al., 2019). It is necessary to appropriately address this issue and give more possibilities and government assistance to kids by teaching them at a young age and making them aware of their responsibilities.

Pakistan, like any other developing country, suffered a severe setback as a result of COVID-19. The entire country was put under lockdown during the first wave. Many industries were left with no choice but to reduce their workforces or close permanently. Those with entrepreneurial expertize and education, on the other hand, saw it as an opportunity. As a result, a large number of new SMEs arose, many of which prospered. The study's relevance stems from the need of having entrepreneurial expertize to deal with future unanticipated occurrences. Because the Pakistani society is more insistent on getting a suitable job than on helping or encouraging young people to establish their own business. This problem has resulted in greater employment demand than supply. As a result, Pakistan had a large number of job losses last year.

The goal of this study was to influence the cultural attitude of the Pakistani people, a society in which having a stable job is favored and appreciated above establishing a business. There aren't many universities in Pakistan that are completely focused on entrepreneurship education. Pakistan's government developed a detailed strategy for the newly formed SME task force, which aims to create an enabling environment and provide assistance to businesses (SME-led Economic Growth, Job Creation, and Poverty Reduction, SME Policy). Pakistan's unemployment crisis has been escalating for several years. With $4.45 \%$ unemployment in 2019 , the unemployment rate is quite high. Furthermore, degree holders' career opportunities are heavily reliant on both the governmental and private sectors. To address these problems and challenges, it is thought that a reexamination of the higher education system is required to overcome the barriers that obstruct expansion and progress. In Pakistan, there hasn't been much research done on this issue. By analyzing entrepreneurial traits among university students, this article will add to this particular field of entrepreneurship.

Based on the theory of planned behavior (Ajzen, 1991), The purpose of this study is to look at the influence of entrepreneurial education (locus of control, co-curricular activities, and entrepreneurial curriculum) in developing entrepreneurial intuitions among university students. This research will aid in the development of a clear strategy to encourage entrepreneurship at the national level for our present and future generations, particularly graduate and postgraduate students so that they may be developed and capable of becoming good entrepreneurs and tackling any unforeseen events in the future.

\section{LITERATURE REVIEW}

\section{University Curriculum}

A curriculum is defined as a set of courses or subjects offered in any educational institute (Egan, 1978). It provides the institutions 
with a guideline or a course of action based on which the learning process occurs, and objectives are achieved. The term curriculum can be taken as the backbone of the education system. A welldesigned curriculum helps you move in the right direction and assists in achieving goals. It is designed to develop fundamental concepts at a very early stage. It then refines Individuals to perform advanced and complex skills (Young, 2014).

Worldwide, different curricula and syllabi are being employed in universities to develop students' specific skills. However, many scholars have focused explicitly on developing entrepreneurial curricula that should be dynamic and versatile in nature (Pillai et al., 2019; Riesterer, 2019). The entrepreneurial curricula must depict a learning experience course possible by merging theoretical and knowledge base teaching with a substantial practical approach. Such a versatile combination of courses and curricula can be best catered to with master's studies. The master's in entrepreneurship program needs some amendments that must have innovative and creative subjects apart from teaching managerial issues (Welter and Gartner, 2016; Ndou et al., 2019; Huang-Saad et al., 2020). This will help make the foundation for the education and knowledge process and provide a concrete and everlasting base to the economy. The other important aspect related to the curricula is its significant role in attitude development toward entrepreneurship. As living in a global village, entrepreneurial studies must be coherent apart from being dynamic and versatile. So, To standardize education with the latest trends, there must be "Internationalization" of curricula for Entrepreneurship (Guillotin, 2018).

Through different researches, it is explored that most of the young generation are now unemployed (Blustein et al., 2020). Unemployment was one of the biggest concerns for societies even before the COVID-19 pandemic. Unemployed are keen to start their own business, and they are passionate about entrepreneurship. However, the lack of theoretical knowledge makes it hard for them. Therefore, students must have the necessary theoretical know-how of the business world to start their entrepreneurial venture (Weber, 2015). In this way, they can minimize the chances of failure. Universities can cater to this thirst by offering relevant courses of entrepreneurship in their curricula.

If intelligently structured and then employed in higher education, the curriculum is the entity that can give fruitful results regarding entrepreneurship. It will foster potential students' interest in having their enterprises and motivate them to think outside the box (Saeed et al., 2015). As entrepreneurship is a risky field, it will take some time to change students' mindsets. Regarding the regulatory focus theory, It is argued that exposure to the entrepreneurship course, whether it is practically or theoretically oriented, creates a motivational element (Piperopoulos and Dimov, 2015). The students should be more exposed to education on entrepreneurship. It has been observed the students who intend to study it get benefitted from it and are more inclined toward the business. The study also corresponds to the theory of planned behavior as the students exposed to entrepreneurial education have developed entrepreneurship's intention (Piperopoulos and Dimov, 2015).
Nowadays, the most widely studied courses of entrepreneurship at the university levels are grouped into three broad categories: 1) Entrepreneurial business creation and management (Fairlie and Fossen, 2018); 2) Entrepreneurship: a historical perspective (Toms et al., 2020); and 3) Entrepreneurship in specific contexts (Dodd et al., 2016). According to the research by Guerrero et al. (2014), adequately designed curriculum and $\mathrm{R} \& \mathrm{D}$ in entrepreneurship can lead to better results at universities. It is evident from the prevailing literature related to the curriculum; it is challenging to teach a practical and intellectual subject theoretically. But teaching entrepreneurship somehow makes the thoughts present in the far-flung areas of the human mind into realities. Thus, this can encourage our young graduates toward entrepreneurship by giving them an educational system fully equipped with a practical and theoretical curriculum that can broaden their thinking horizons and nurture their potential capability.

H1: University curriculum has a direct relationship with attitude development toward entrepreneurial intentions.

\section{Co-Curricular Activities}

Co-curricular activities are voluntary activities that are out of the scope of the regular curriculum. They support educational activities and enhance social interaction, leadership, healthy recreation, self-discipline, and self-confidence (Batool and Raiz, 2019). Co-curricular activities provide an informal platform for interaction that helps a student or an individual in self-actualization. Educational institutes have quite diverse students, and this informal interaction will help students in the practical and creative exploitation of their hidden capabilities. Besides, entrepreneurship is more a practical subject that becomes boring and less interesting without practicality in teaching (Huang-Saad et al., 2020). Cocurricular activities can help in making it more interesting besides being challenging. It is a big challenge for the curriculum developers to make the courses aligned to their entrepreneurial needs and motivation. University students should be more exposed to entrepreneurial studies and cocurricular activities, increasing self-motivation (Kuratko and Morris, 2018).

These activities also help in developing leadership qualities and motivate the risk-taking attitude of students. This makes them courageous enough to endure challenges for their benefit and creativity, which in the long run can be seen as a positive sign toward entrepreneurship (Volkmann and Audretsch, 2017; Preedy et al., 2020). The universities are restructuring their settings to make them more congenial and in line with the objective of entrepreneurship. Universities can make it happen by following a comprehensive approach that includes weekly workshops, semester-wize business plan competitions, conferences, seminars. Entrepreneurial universities can provide the student with more environment to take new challenges and excel (Guerrero et al., 2014). Furthermore, researchers envisaged that such co-curricular activities with some experiential backup would help impart the subject matter's practical knowledge to the graduates (Preedy, 2018; Firmansyah et al., 2020). 
In today's era, entrepreneurship is one of the fastest-growing disciplines at universities and colleges. There is much focus on the practical implication and learning of entrepreneurship rather than just traditional wisdom (Preedy et al., 2020). On the other hand, students have reported that co-curricular activities help better understand these skills. Universities can effectively play their role when plenty of funds are available at their disposal and government policies to assist them. Therefore, to make it a real success society, government and universities must join hands designing programs that involve co-curricular activities related to entrepreneurship. Presume government assistance is provided to students at an early level, and resources are made available. In that case, much burden can be taken from parents and donors (Lazaro and Anney, 2016).

$\mathrm{H} 2$ : Cocurricular activities have a direct relationship with attitude development toward entrepreneurial intentions.

\section{Locus of Control}

Locus of control is defined as the influencing factors behind any decision or action (Spector, 1982). The locus of control can be internal or external. The external locus includes the environmental factor, i.e., society, culture. In contrast, the internal locus consists of the personal drive to achieve something or passion (MacDonald, 1971). It is a two-way process like universities trying to make their curricula and the environment more congenial to support and promote entrepreneurship. It is also upon the will of graduates what they opt for themselves as a career choice.

Internal factors have shown more influence on the decisionmaking of a person. Empirical results have shown that people are not willing for a risky venture. An entrepreneurial venture is possible only when the student is full of zest for that particular venture (Yurtkoru et al., 2014; Wu et al., 2018). The Post COVID19 developmental stage of the market economy has raised an urge for entrepreneurship mindsets. It has become a very urgent issue involving youth in business as they have the most creative ways of thinking. They have high standards and internal motivation to decrease the employment issue to a much extent.

The other aspect related to locus of control in literature is people who are not employed previously. Taking the example of young graduates, who are least bothered about the risk factor, they are highly compelled to achieve and do something creative and worthy. An entrepreneurial person endures challenges and makes things right for others (Antoncic et al., 2018). They must have a strong sense of self-efficacy and self-actualization and a firm belief in their capabilities. Many researchers have also validated this concept that entrepreneurs have a strong locus of control (Asante and Affum-Osei, 2019; Kusumawijaya, 2019).

While researchers talk about the internal locus of control as more significant, they can't forget to quote that being an entrepreneur is an inherited or by-birth gift in entrepreneurs most often. These enduring nature capabilities like risk-taking and creative thinking are enhanced through comprehensive training in universities (Riesterer, 2019). In the past decade, it has been noticed that women have shown a substantial role in any country's economic growth. When they are exposed to entrepreneurial opportunities, they have performed great and contribute a lot to strengthening the economy (Hasan et al., 2016). Therefore, the youth needs to be encouraged for opting entrepreneurship to change the future of any country.

Researches have further envisaged that we can motivate an individual with an internal locus of control to become entrepreneurs. However, they need an environment that nurtures this passion for creativity (Trippl et al., 2015). Universities can effectively play this role by providing opportunities, a network of experienced faculty, and an appropriate amalgamation of curricular and co-curricular activities.

H3: Locus of control has a direct relationship with attitude development toward entrepreneurial intentions.

To sum up, this research aims to discuss the impact of the University curriculum, Locus of control, and extracurricular activities on entrepreneurial intentions among university students based on the theory of planned behavior. The theoretical model can be seen in Figure 1.

\section{METHODOLOGY}

\section{Data Collection}

The questionnaire was designed on a weblink and disseminated among the students through social websites, teachers, and friends in 15 universities of Pakistan. In order to avoid the homology deviation, a two-point data collection method was adopted, and the data was collected by referring to the literature of similar research topics. A code was assigned to each survey object, and they were asked to use the same code to fill out the questionnaires at two time points. The first phase was conducted in March 2020. 700 questionnaires were rolled out to students to acquire data against variables of University curriculum, Entrepreneurial intentions, and demographic information (gender, age, and education). Upon assessments of 630 returned questionnaires, 622 were effective. The second phase of the data collection was conducted in June 2020, and 622 questionnaires were sent back to collect data on the variables of Locus of control and extracurricular activities. Out of 622 questionnaires, 562 were received. Incomplete and influenced questionnaires were deleted, and 536 valid questionnaires were used for this study, with a response rate of $76.5 \%$. All the research processes were rigorously monitored and standardized. Participants were asked to complete the survey items uniformly within the prescribed time limit, and the purpose of the research was conveyed to participants. Therefore, the objectivity, confidentiality, and authenticity of the collected data were ensured to a certain extent.

In the effective sample subject, the proportion of male students was $80.4 \%$. The proportion of students aged $18-22$ was $16.9 \%$, the proportion of aged 23-27 was 50.9\%, the proportion of aged $27-31$ was $17.3 \%$, the proportion of aged $32-36$ was $14.7 \%$. The proportion of students in early years (0-2) of bachelor's degree was $12.6 \%$, the proportion of students in final years $(2-4)$ of bachelor's degree was $30 \%$, the proportion of students in master's degree was $53.5 \%$, and proportion of Ph.D. was $3.7 \%$. 


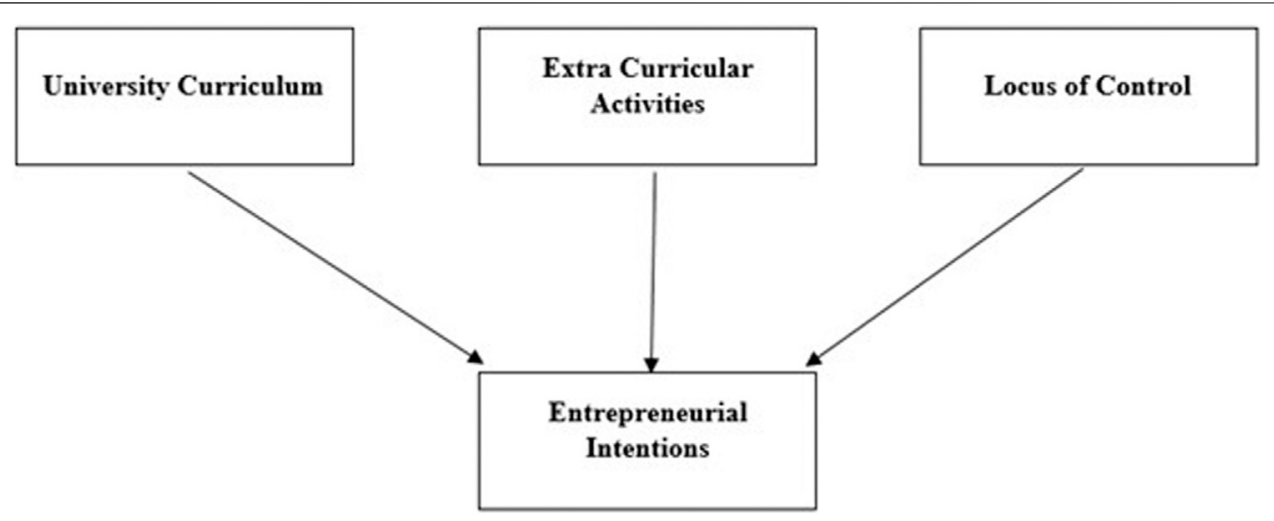

FIGURE 1 | Theoretical model.

\section{Measures and Variables}

In order to ensure the reliability and validity of the scales, this study adopted the scales from published literature in authoritative journals. All questionnaires were scored with Likert's 7 points, from 1 to 7 indicating "strongly disagree" to "strongly agree" (Appendix).

\section{Extracurricular Activities}

This research measured extracurricular activities through the two items scale by Toyokawa (Toyokawa and Toyokawa, 2002). One of the scale items states, "I have made an effort to become involved in various extracurricular activities." Respondents had to scores against a Likert 7-point scale. The higher scores relate to a better assessment of extracurricular activities. Cronbach's Alpha reliability of the scale was reported as 0.891 .

\section{Internal Locus of Control}

Internal locus of control was measured through three items scale developed by Levenson and Miller (Levenson and Miller, 1976). One of the scale items states, "When I make plans, I am almost certain to make them work." This research used a Likert 7-point scale to measure Internal locus of control. Cronbach's Alpha was 0.759 in this research, which met the basic standard of psychometrics.

\section{Entrepreneurial Intentions}

For measuring entrepreneurial intentions, the scale used in this research was developed by Krueger et al. (2000), having a Cronbach Alpha value of 0.891. Responses were collected using a 7-point Likert scale. One of the eight items states, "I do my best to run my own business."

\section{Curriculum}

The curriculum was measured through nine items scale designed by De young (Boerschig and De Young, 1993). One of the scale items states, "The subject of entrepreneurship interests me very much because of interactive learning." This research used a Likert 7-point scale to measure curricula. The scale reported a high Cronbach's Alpha reliability of 0.815 .

\begin{tabular}{|c|c|c|c|c|c|c|c|}
\hline Model & $\chi^{2}$ & df & $\chi^{2 / d f}$ & RMSEA & CFI & IFI & TLI \\
\hline Four factors & 724.101 & 203 & 3.567 & 0.071 & 0.914 & 0.915 & 0.988 \\
\hline Three factors & 1668.806 & 206 & 8.101 & 0.115 & 0.796 & 0.797 & 0.771 \\
\hline Two factors & 2375.776 & 208 & 11.422 & 0.140 & 0.698 & 0.699 & 0.664 \\
\hline One factor & 3653.32 & 209 & 17.480 & 0.176 & 0.520 & 0.521 & 0.469 \\
\hline
\end{tabular}

\section{Control Variables}

Based on a review of existing literature, this research found that demographic information may affect employees' mental state and behavioral responses, profoundly affecting this study's results. So demographic information should be controlled during the analysis process. This demographic information included: Gender, age, and education.

\section{Ethical Issues}

The research was granted access by the ethics committee COMSATS University, Islamabad, Pakistan and School of Management, Jiangsu University, Zhenjiang, People's Republic of China. The linkages between the Pakistan universities supported in getting the approvals from participating universities. The participating students were informed, and all the participants provided the written consent. The research was conducted in compliance with the Declaration of Helsinki. This study received funding from Jiangsu University and JiangSu Haicore Technology Joint Stock Co., LTD. The funder was not involved in the study design, collection, analysis, interpretation of data, the writing of this article or the decision to submit it for publication. All authors declare no other competing interests.

\section{RESULTS}

\section{EFA and CFA}

Harmon single factor analysis was adopted in this research to check the exploratory factor analysis (EFA) across the variables. The results presented the value of $\mathrm{KMO}=0.888$, Bartlett's spherical (Tobias and Carlson, 1969) test presented the Chi- 
TABLE 2 | Descriptive statistics and correlation analysis.

\begin{tabular}{|c|c|c|c|c|c|c|c|c|c|}
\hline & MEAN & SD & 1 & 2 & 3 & 4 & 5 & 6 & 7 \\
\hline 1 GENDER & 1.1959 & 0.39726 & 1 & & & & & & \\
\hline 2 AGE & 2.3116 & 0.95013 & 0.036 & 1 & & & & & \\
\hline 3 EDUCATION & 2.4832 & 0.76102 & $-0.085^{\star}$ & $-0.390^{\star \star \star}$ & 1 & & & & \\
\hline 4 LOC & 6.0877 & 0.80613 & 0.081 & $-0.143^{\star \star}$ & $0.097^{\star}$ & 1 & & & \\
\hline 5 UC & 5.2174 & 1.29660 & 0.042 & $-0.122^{\star \star}$ & -0.037 & $0.274^{\star \star \star}$ & 1 & & \\
\hline 6 ECA & 5.3412 & 0.99683 & 0.034 & $-0.154^{\star \star \star}$ & 0.011 & $0.278^{\star \star \star}$ & $0.764^{\star \star \star}$ & 1 & \\
\hline 7 ES & 5.7215 & 0.93503 & 0.012 & -0.052 & $0.086^{\star}$ & $0.637^{\star \star \star}$ & $0.377^{\star \star \star}$ & $0.388^{\star \star \star}$ & 1 \\
\hline
\end{tabular}

Note: LOC (locus of control), UC (university curriculum), ECA (extracurricular activities), ES (entrepreneurial intentions). F value is a test of the overall significance of all explanatory variables. The R-squared value indicates how well the model fits the sample data.

TABLE 3 | Hypothesis testing.

\begin{tabular}{|c|c|c|c|c|c|c|}
\hline \multirow[t]{2}{*}{ Variable } & \multicolumn{6}{|c|}{ ES } \\
\hline & Model 1 & & & Model 2 & & \\
\hline \multicolumn{7}{|c|}{ Control variable } \\
\hline Gender & 0.046 & -0.154 & 0.246 & -0.099 & -0.247 & 0.048 \\
\hline Age & -0.021 & -0.112 & 0.069 & $0.094^{* *}$ & 0.027 & 0.162 \\
\hline Education & 0.098 & -0.016 & 0.211 & 0.083 & -0.001 & 0.166 \\
\hline LOC & & & & $0.664^{*+*}$ & 0.588 & 0.740 \\
\hline UC & & & & $0.086^{*}$ & 0.016 & 0.156 \\
\hline ECA & & & & $0.144^{* *}$ & 0.053 & 0.235 \\
\hline $\mathbf{F}$ & 1.473 & & & $78.083^{*+* t}$ & & \\
\hline $\mathrm{R}^{2}$ & 0.008 & & & 0.470 & & \\
\hline$\triangle \mathbf{R}^{2}$ & 0.008 & & & 0.461 & & \\
\hline
\end{tabular}

LOC (locus of control), UC (university curriculum), ECA (extracurricular activities), ES (entrepreneurial intentions). Fvalue is a test of the overall significance of all explanatory variables. The Rsquared value indicates how well the model fits the sample data.

Note: ${ }^{*} \mathrm{p}<0.05,{ }^{* *} \mathrm{p}<0.01,{ }^{* * *} \mathrm{p}<0.001$.

square value of $7288.999(p<0.001)$. The four common factors extracted were consistent with the number of variables set in this study. The first-factor variability was $36.9 \%$, which is lower than the critical value of $50 \%$ (Nagao, 1973). The results deemed the data free from serious common method bias issues. Furthermore, The data collection process was conducted anonymously under strict control to avoid any common method deviation.

This study used AMOS 24.0 to test the discriminant validity of the variables. The results of the confirmatory factor analysis (CFA) are shown in Table 1. The results obtained from CFA suggests that the fourfactor model fits the index best $\left(\chi^{2} / \mathrm{df}=3.567<5\right.$, RMSEA $=0.071<$ 0.08 , CFI $=0.914>0.9$, TLI $=0.988>9$ ). These results are better in comparison to the combined effect of three-factor, two-factor, and singlefactor models. Hence, this confirms the factors of internal locus of control, curriculum, extracurricular activities, and entrepreneurial intentions have good discriminative validity. This study used standard factor loadings from CFA to calculate CR and AVE. Every factor loading is higher than 0.50 , stating that the variables have good convergent validity.

\section{Descriptive Statistics and Correlation Analysis}

In order to further explore the correlation between extracurricular activities, internal locus of control, entrepreneurial intentions, and curriculum, the data was analyzed using SPSS 20.0 software. Descriptive statistics and correlation analysis results are exhibited in Table 2: locus of control is positively related to entrepreneurial intentions $(r=$ 0.637, $p<0.001$ ), the curriculum is positively related to entrepreneurial intentions $(r=0.377, p<0.001)$, extracurricular activities is positively related to entrepreneurial intentions $(r=0.388, p<0.001)$. Therefore, the results preliminarily verified the theoretical hypothesis of this research.

\section{Hypothesis Testing}

This study tested the effect of internal locus of control, curriculum, extracurricular activities on entrepreneurial intentions through regression analysis shown in Table 3. In the regression equation model, gender, age, education level are first taken as control variables. Then regression analysis is conducted on the utility of target variables, respectively. The operational steps are conducted to explore the effect of internal locus of control on entrepreneurial intentions, the effect of curriculum on entrepreneurial intentions, and the effect of extracurricular activities on entrepreneurial intentions.

The results indicate that locus of control positively affects entrepreneurial intentions $(\beta=0.664, p<0.001)$ and support hypothesis 1 . In the case of curriculum on entrepreneurial 
intentions, the results support the positive relationship $(\beta=0.086$, $p<0.05)$ and support hypothesis 2 . Hypothesis 3 suggested that extracurricular activities positively affect entrepreneurial intentions, and the results were supported correspondingly ( $\beta$ $=0.144, p<0.01$ ).

\section{DISCUSSION}

COVID-19 has wreaked havoc on the globe in a variety of ways, affecting virtually everyone in some capacity. Many people lost loved ones, and many more were financially impacted. However, one of the most pressing problems these days is the deterioration of economies and the shortage of employment opportunities. Young people were also impacted in a variety of ways, including disruptions in training/education, a drop in new job entrants, and income losses.

This study investigated three entrepreneurship-related qualities: curriculum, locus of control, and extracurricular activities, using the psychological characteristics school of thinking. Table 3's findings, as well as the study's connections, were statistically significant. Additionally, in this study, locus of control was found to be the strongest predictor of entrepreneurial goals among students. This study was carried out to encourage workers to pursue entrepreneurship and to look at the variables that are required for such goals. This study focused on the impact of locus of control on entrepreneurial ambitions. The impact of curriculum on entrepreneurial ambitions was also assessed. Finally, the impact of extracurricular activities on entrepreneurial goals was investigated. The findings of this study are in line with those of earlier studies.

\section{Theoretical Contribution}

This study concluded from correlation analysis and Table 3 that locus of control is the strongest predictor of entrepreneurial intentions than curriculum and extracurricular activities. Previous studies have also proposed a strong relationship between locus and control variables and entrepreneurial intentions (Asante and Affum-Osei, 2019; Kusumawijaya, 2019). When people have reasonable control over the events happening in their daily lives, they will feel more confident and trigger entrepreneurial intentions. This study concludes that current events and happenings cannot affect entrepreneurial intentions. Instead, individuals utilize it as an opportunity (Ibrahim and Mas'ud, 2016; Wang et al., 2016). Efforts and one's own beliefs are significant for shaping the future. Individuals with firm faith and persistence in achieving the desired goal are considered an essential predictor of entrepreneurial intentions. A person must be internally motivated because failures in start-up periods decrease the motivation level and society also discourages this risky occupation. So, an entrepreneur must have strong will-power and passion for proving him (Fellnhofer, 2017). Students with a strong locus of control can positively affect the entrepreneurial intentions. Consequently, this research enriched the theoretical and practical research results of locus of control on entrepreneurial intentions.
The curriculum can also be a very effective tool in attitude development toward entrepreneurship. When the universities' curriculum is dynamic, universities inculcate new courses with time, like project management. An effective curriculum can help support and motivate the students who are seeking entrepreneurship as a career choice. The results of this study are consistent with the finding of Val et al. (2017). They supported the idea of an effective curriculum in upbringing entrepreneurial intentions among students. Adapting to the new ways and teaching techniques with improved curricula can promote entrepreneurial intentions, which is also suggested by Pillai et al. (2019).

This study also concluded that extracurricular activities are the least effective on entrepreneurial intentions among students. However, we cannot ignore the role of such activities in the development of students. Findings suggest that extracurricular activities offer practical and social learning prospects for students. This study is consistent with the earlier findings that, Engaging in extracurricular activities (business talks, competitions, and student clubs) develops students' confidence and practical knowledge (Milner et al., 2016). Consequently, theoretical and empirical research results of extracurricular activities on entrepreneurial intentions are enhanced in this research.

\section{Practical Implications}

Education on entrepreneurship has become the driving wheel for developing countries and a priority element for policymakers during this challenging time. COVID-19 has struck almost all parts of the globe and created a job deficit. The large organization has opted for downsizing, and many people lost their jobs. However, SMEs have been in the spotlight of this period. Many SMEs acted timely to this situation and shifted to online setups. They instead took it as an opportunity to look into new ventures and services. This is all because of entrepreneurial education and the knowledge they had. This research indicates that entrepreneurship interventions into the education system are expected to create a society that brings economic benefits and enterprising behavior that benefits the existing SME and helps create new ventures. At the advanced phase of refining the market economy, youth entrepreneurship improvement issues have become more pressing. Youth, who has an imaginative state of mind and is directed to maintaining their particular businesses and innovation and risk, and who has the most elevated standard of information of the Internet advancements, is a part of the society. Drawing youth into the business environment elevates to tackling the employment issue in the labor market. Entrepreneurship is a risky field, and it requires much self-belief. Therefore universities must foster their students and provide conditions that build a locus of control.

Many scholars in the past have stressed that the locus of control relates to business success and creation (Asante and Affum-Osei, 2019; Kusumawijaya, 2019). This study's results supported the previous research and emphasized the importance of locus of control heavily. Compared with other variables, locus of control is the most prominent factor in upbringing the entrepreneurial intention. Therefore universities should pay the utmost attention to motivate their 
students, providing them with more chances to interact socially. So they can polish their skills through seminars, workshops, conferences, and competitions. To summarize, this study helps universities design their entrepreneurial curricula with a mix of extracurricular activities. This will internally motivate the students to practice their skills and overcome the fear of failure.

\section{Limitations and Future Directions}

This research also inevitably has some limitations. Firstly, this research collected time-lagged data in COVID-19 times. The recency effect will cause the students to rate their entrepreneurial intentions at a higher level. Since the job market is declining and many people have lost their jobs, it is hard to find the new one. There is a high debate on having your small setup rather than dependent on others in future pandemics. Therefore, the recent events might have affected people's mindsets (Hopman et al., 2020). A further vertical investigation should be carried out for a relatively long period to determine a direct causal relationship. The obtained data test results will be more reliable.

Secondly, other control variables related to entrepreneurial intentions are not set except for demographic information factors discussed in this study. In this research, we set gender as a control variable. However, the data analysis result exhibited gender significantly affecting entrepreneurial intention (Guzman and Kacperczyk, 2019). Future studies should include the moderating/ mediating role of gender to test if gender will affect this relationship. Cultural aspects need to be addressed and affect people's mindsets (Fritsch and Wyrwich, 2017). Risk-takers cultures promote and support the idea of entrepreneurial initiatives.

Moreover, personality traits can be a vital element as well. The need for achievement is positively linked to entrepreneurial intentions (Çolakoğlu and Gözükara, 2016). Risk tolerance is considered a positive factor in promoting entrepreneurial intentions (Karabulut, 2016), and entrepreneurial alertness can enhance individuals' entrepreneurial intentions (Obschonka et al., 2017). Therefore an in-detailed study of all the personality trait factors can help better understand the relationship's nature.

Thirdly, the entrepreneurial event theory can explain cultural and social factors' interaction on the individuals' entrepreneurial intentions (Kuehn, 2008). Since business and other studies students have different approaches and exposure toward entrepreneurship, this study has explored students' entrepreneurial choices as a whole. Future research should focus on designing the model to meet specific studies' programs. Lastly, this study analyzed data from 536 students in all the educations sectors (universities) of Pakistan. Further research needs to use various teaching methods taught at different levels. Teaching methods (successful entrepreneurial stories,

\section{REFERENCES}

Akpan, I. J., Udoh, E. A. P., and Adebisi, B. (2020). Small Business Awareness and Adoption of State-Of-The-Art Technologies in Emerging and Developing Markets, and Lessons from the COVID-19 Pandemic. J. Small Business Entrepren. 2, 1-18. doi:10.1080/08276331.2020.1820185 failure stories and survival, practical learning, and support in learning) need to be addressed. Therefore, future studies with an extended sample can better understand education's role in students' entrepreneurial intentions.

\section{CONCLUSION}

Seeking for the word entrepreneurship, the first thing that comes to mind is "Setting up a New Enterprise," but it is more. Entrepreneurship is a broad term that defines people's jeopardized attitude for value creation in employment generation, making profits. Optimal use of limited resources in the most creative way to maximize the benefits of creating jobs and supporting the economy in hard times like COVID-19, there is an immense need to go toward the last resort of enterprising economies by training youth for entrepreneurship. Educational institutions can play a vital role by dynamically participating through their efficient and proficient curricula and skilled faculty by a blend of curricular and co-curricular activities to the new generation.

\section{DATA AVAILABILITY STATEMENT}

The raw data supporting the conclusion of this article will be made available by the authors, without undue reservation.

\section{ETHICS STATEMENT}

The studies involving human participants were reviewed and approved by the research was granted access by the ethics committee COMSATS University, Islamabad, Pakistan and School of Management, Jiangsu University, Zhenjiang, People's Republic of China. The patients/participants provided their written informed consent to participate in this study.

\section{AUTHOR CONTRIBUTIONS}

All authors listed have made a substantial, direct, and intellectual contribution to the work and approved it for publication.

\section{FUNDING}

This research is supported by Jiangsu University and JiangSu Haicore Technology Joint Stock Co., LTD.

Antoncic, J. A., Antoncic, B., Gantar, M., Hisrich, R. D., Marks, L. J., Bachkirov, A. A., et al. (2018). Risk-Taking Propensity and Entrepreneurship: The Role of Power Distance. J. Enterprising Cult. 26, 1-26. doi:10.1142/s0218495818500012

Asante, E. A., and Affum-Osei, E. (2019). Entrepreneurship as a Career Choice: The Impact of Locus of Control on Aspiring Entrepreneurs' Opportunity Recognition. J. Business Res. 98, 227-235. doi:10.1016/j.jbusres.2019.02.006 
Batool, T., and Raiz, J. (2019). Variations in Parental Participation in Curricular and Co-curricular Activities of university Students. Glob. Soc. Sci. Rev. 4 (4), 239-249. doi:10.31703/gssr.2019(iv-iv).31

Blustein, D. L., Duffy, R., Ferreira, J. A., Cohen-Scali, V., Cinamon, R. G., and Allan, B. A. (2020). Unemployment in the Time of COVID-19: A Research Agenda. J. Vocat. Behav. 119, 103436.

Boerschig, S., and De Young, R. (1993). Evaluation of Selected Recycling Curricula: Educating the green Citizen. J. Environ. Edu. 24 (3), 17-22. doi:10.1080/ 00958964.1993.9943498

Çolakoğlu, N., and Gözükara, İ. (2016). A Comparison Study on Personality Traits Based on the Attitudes of university Students toward Entrepreneurship. Procedia-Social Behav. Sci. 229, 133-140. doi:10.1016/j.sbspro.2016.07.122

Crayne, M. P. (2020). The Traumatic Impact of Job Loss and Job Search in the Aftermath of COVID-19. Psychol. Trauma Theor. Res. Pract. Pol. 12 (S1), S180-S182. doi:10.1037/tra0000852

Dias, F. A., Chance, J., and Buchanan, A. (2020). The Motherhood Penalty and the Fatherhood Premium in Employment during Covid-19: Evidence from the united states. Res. Soc. Stratification Mobility 69, 100542. doi:10.1016/ j.rssm.2020.100542

Dodd, S. D., Pret, T., and Shaw, E. (2016). "Advancing Understanding of Entrepreneurial Embeddedness: Forms of Capital, Social Contexts and Time," in A Research Agenda for Entrepreneurship and Context. UK: Edward Elgar Publishing.

Egan, K. (1978). What Is Curriculum? Curriculum Inq. 8 (1), 65-72. doi:10.1080/ 03626784.1978.11075558

Fairlie, R. W., and Fossen, F. M. (2018). Opportunity versus Necessity Entrepreneurship: Two Components of Business Creation (January 30, 2018). CESifo Working Paper Series No. 6854. Available at: https://ssrn. com/abstract $=3140340$

Farsi, J. Y., Imanipour, N., and Salamzadeh, A. (2012). Entrepreneurial university Conceptualization: Case of Developing Countries. Glob. Business Manag. Res. Int. J. 4 (2), 193-204.

Fellnhofer, K. (2017). The Power of Passion in Entrepreneurship Education: Entrepreneurial Role Models Encourage Passion? J. Entrep Educ. 20 (1), 58-87.

Firmansyah, F., Rahayu, W., and Nurjannah, N. (2020). Evaluation of the Entrepreneurship Education Program through Extracurricular Activities of Student Company. Jurnal Penelitian Dan Evaluasi Pendidikan 24 (1), 51-61. doi:10.21831/pep.v24i1.19783

Fitriasari, F. (2020). How Do Small and Medium Enterprise (SME) Survive the COVID-19 Outbreak?. Jurnal Inovasi Ekonomi 5 (02), 53-62. doi:10.22219/ jiko.v5i3.11838

Fritsch, M., and Wyrwich, M. (2017). The Effect of Entrepreneurship on Economic Development-An Empirical Analysis Using Regional Entrepreneurship Culture. J. Econ. Geogr. 17 (1), 157-189. doi:10.1093/jeg/lbv049

Guerrero, M., Urbano, D., and Fayolle, A. (2016). Entrepreneurial Activity and Regional Competitiveness: Evidence from European Entrepreneurial Universities. J. Technol. Transf 41 (1), 105-131. doi:10.1007/s10961-014-9377-4

Guerrero, M., Urbano, D., and Salamzadeh, A. (2014). "Evolving Entrepreneurial Universities: Experiences and Challenges in the Middle Eastern Context," in Handbook on the Entrepreneurial University. Cheltenham, United Kingdom: Edward Elgar Publishing.

Guillotin, B. (2018). Strategic Internationalization through Curriculum Innovations and Stakeholder Engagement. J. Int. Edu. Business 11, 2-26. doi:10.1108/jieb-04-2017-0015

Guzman, J., and Kacperczyk, A. (2019). Gender gap in Entrepreneurship. Res. Pol. 48 (7), 1666-1680. doi:10.1016/j.respol.2019.03.012

Hasan, F. S. M. A., Almubarak, M. M. S., and Ahmed, A. (2016). Factors Influencing Women Entrepreneurs' Performance in SMEs. World J. Entrep. Manag. Sustain. Dev. 12. doi:10.1108/wjemsd-09-2015-0037

Hopman, J., Allegranzi, B., and Mehtar, S. (2020). Managing COVID-19 in Lowand Middle-Income Countries. Jama 323 (16), 1549-1550. doi:10.1001/ jama.2020.4169

Huang-Saad, A., Bodnar, C., and Carberry, A. (2020). Examining Current Practice in Engineering Entrepreneurship Education. Los Angeles, CA: SAGE Publications Sage CA.

Ibrahim, N. A., and Mas'ud, A. (2016). Moderating Role of Entrepreneurial Orientation on the Relationship between Entrepreneurial Skills,
Environmental Factors and Entrepreneurial Intention: A PLS Approach. 10.5267/j.msl 6 (3), 225-236. doi:10.5267/j.msl.2016.1.005

Karabulut, A. T. (2016). Personality Traits on Entrepreneurial Intention. Proced. Soc. Behav. Sci. 229, 12-21. doi:10.1016/j.sbspro.2016.07.109

Kawamorita, H., Salamzadeh, A., Demiryurek, K., and Ghajarzadeh, M. (2020). Entrepreneurial Universities in Times of Crisis: Case of COVID-19 Pandemic. J. Entrepreneurship, Business Econ. 8 (1), 77-88.

Krueger, N. F., Jr, Reilly, M. D., and Carsrud, A. L. (2000). Competing Models of Entrepreneurial Intentions. J. Business Venturing 15 (5-6), 411-432. doi:10.1016/s0883-9026(98)00033-0

Kuehn, K. W. (2008). Entrepreneurial Intentions Research: Implications for Entrepreneurship Education. J. Entrepreneurship Edu. 11, 87.

Kuratko, D. F., and Morris, M. H. (2018). Examining the Future Trajectory of Entrepreneurship. J. Small Business Manag. 56 (1), 11-23. doi:10.1111/ jsbm. 12364

Kusumawijaya, I. K. (2019). The Prediction of Need for Achievement to Generate Entrepreneurial Intention: A Locus of Control Mediation. Irmm 9 (4), 54-62. doi: $10.32479 /$ irmm. 8330

Lazaro, A., and Anney, V. N. (2016). Rethinking the Role of Co-curricular Activities in Developing Students' Talents in Secondary Schools in Tanzania. J. Emerging Trends Educ. Res. Pol. Stud. 7 (2), 152-166.

Levenson, H., and Miller, J. (1976). Multidimensional Locus of Control in Sociopolitical Activists of Conservative and liberal Ideologies. J. Personal. Soc. Psychol. 33 (2), 199-208. doi:10.1037/0022-3514.33.2.199

Loayza, N. V., and Pennings, S. (2020). Macroeconomic Policy in the Time of COVID-19: A Primer for Developing Countries. London: World bank. doi: $10.1596 / 33540$

Long, W. (1983). The Meaning of Entrepreneurship. Am. J. Small Business 8 (2), 47-59. doi:10.1177/104225878300800209

Lord, P. (2020). Incentivising Employment during the COVID-19 Pandemic. Theor. Pract. Legis. 8 (3), 355-372. doi:10.1080/20508840.2020.1792635

MacDonald, A. P. (1971). Internal-external Locus of Control: Parental Antecedents. J. Consulting Clin. Psychol. 37 (1), 141-147. doi:10.1037/h0031281

Meoli, A., Fini, R., Sobrero, M., and Wiklund, J. (2020). How Entrepreneurial Intentions Influence Entrepreneurial Career Choices: The Moderating Influence of Social Context. J. Business Venturing 35 (3), 105982. doi:10.1016/j.jbusvent.2019.105982

Milner, S., Cousins, W., and McGowan, I. (2016). Does All Work and No Play Make a Dull Graduate? Perceptions of Extra-curricular Activities and Employability. J. Perspect. Appl. Acad. Pract. 4 (1), 13-18. doi:10.14297/ jpaap.v4i1.183

Nabi, G., Walmsley, A., Liñán, F., Akhtar, I., and Neame, C. (2018). Does Entrepreneurship Education in the First Year of Higher Education Develop Entrepreneurial Intentions? the Role of Learning and Inspiration. Stud. Higher Edu. 43 (3), 452-467. doi:10.1080/03075079.2016.1177716

Nagao, H. (1973). Asymptotic Expansions of the Distributions of Bartlett's Test and Sphericity Test under the Local Alternatives. Ann. Inst. Stat. Math. 25 (1), 407-422. doi:10.1007/bf02479386

Ndou, V., Mele, G., and Del Vecchio, P. (2019). Entrepreneurship Education in Tourism: An Investigation Among European Universities. J. Hospitality, Leis. Sport Tourism Edu. 25, 100175. doi:10.1016/j.jhlste.2018.10.003

Obschonka, M., Hakkarainen, K., Lonka, K., and Salmela-Aro, K. (2017). Entrepreneurship as a Twenty-First century Skill: Entrepreneurial Alertness and Intention in the Transition to Adulthood. Small Bus Econ. 48 (3), 487-501. doi:10.1007/s11187-016-9798-6

Ozaralli, N., and Rivenburgh, N. K. (2016). Entrepreneurial Intention: Antecedents to Entrepreneurial Behavior in the USA and Turkey. J. Glob. Entrepreneurship Res. 6 (1), 1-32. doi:10.1186/s40497-016-0047-x

Pillai, K. R., Upadhyaya, P., Balachandran, A., and Nidadavolu, J. (2019). Versatile Learning Ecosystem: A Conceptual Framework. Higher Edu. Future 6 (1), 85-100. doi:10.1177/2347631118802653

Piperopoulos, P., and Dimov, D. (2015). Burst Bubbles or Build Steam? Entrepreneurship Education, Entrepreneurial Self-Efficacy, and Entrepreneurial Intentions. J. Small Business Manag. 53 (4), 970-985. doi: $10.1111 /$ jsbm. 12116

Preedy, S. (2018). An Examination of Students' Entrepreneurial Learning through Extracurricular Enterprise Activities. Plymouth: University of Plymouth. 
Preedy, S., Jones, P., Maas, G., and Duckett, H. (2020). Examining the Perceived Value of Extracurricular enterprise Activities in Relation to Entrepreneurial Learning Processes. J. Small Business Enterprise Dev. 27, 1085-1105. doi:10.1108/jsbed-12-2019-0408

Riesterer, E. (2019). The Effectiveness of Versatile Curriculum in A-Typical Learners. Anchorage, Alaska: Alaska Pacific University.

Saeed, S., Yousafzai, S. Y., Yani-De-Soriano, M., and Muffatto, M. (2015). The Role of Perceived university Support in the Formation of Students' Entrepreneurial Intention. J. Small Business Manag. 53 (4), 1127-1145. doi:10.1111/jsbm.12090

Salamzadeh, A., Farjadian, A. A., Amirabadi, M., and Modarresi, M. (2014). Entrepreneurial Characteristics: Insights from Undergraduate Students in Iran. Ijesb 21 (2), 165-182. doi:10.1504/ijesb.2014.059471

Spector, P. E. (1982). Behavior in Organizations as a Function of Employee's Locus of Control. Psychol. Bull. 91 (3), 482-497. doi:10.1037/0033-2909.91.3.482

Tobias, S., and Carlson, J. E. (1969). Brief Report: Bartlett's Test of Sphericity and Chance Findings in Factor Analysis. Multivariate Behav. Res. 4 (3), 375-377. doi:10.1207/s15327906mbr0403_8

Toms, S., Wilson, N., and Wright, M. (2020). Innovation, Intermediation, and the Nature of Entrepreneurship: A Historical Perspective. Strateg. Entrepreneurship J. 14 (1), 105-121. doi:10.1002/sej.1310

Toyokawa, T., and Toyokawa, N. (2002). Extracurricular Activities and the Adjustment of Asian International Students: A Study of Japanese Students. Int. J. Intercultural Relations 26 (4), 363-379. doi:10.1016/s0147-1767(02)00010-x

Trippl, M., Sinozic, T., and Lawton Smith, H. (2015). The Role of Universities in Regional Development: Conceptual Models and Policy Institutions in the UK, Sweden and Austria. Eur. Plann. Stud. 23 (9), 1722-1740. doi:10.1080/ 09654313.2015.1052782

Val, E., Gonzalez, I., Iriarte, I., Beitia, A., Lasa, G., and Elkoro, M. (2017). A Design Thinking Approach to Introduce Entrepreneurship Education in European School Curricula. Des. J. 20 (Suppl. 1), S754-S766. doi:10.1080/ 14606925.2017.1353022

Volkmann, C., and Audretsch, D. (2017). "Entrepreneurship Education at Universities," in International Studies in Entrepreneurship (New York: Springer International Publishing AG \& Springer), 1-10.

Wang, J.-H., Chang, C.-C., Yao, S.-N., and Liang, C. (2016). The Contribution of SelfEfficacy to the Relationship between Personality Traits and Entrepreneurial Intention. High Educ. 72 (2), 209-224. doi:10.1007/s10734-015-9946-y
Wannamakok, W., and Liang, W. (2019). Entrepreneurship Education and Entrepreneurial Intention: Perspectives on Institutional Theory. J. Entrepreneurship, Business Econ. 7 (2), 106-129.

Waris, A., Atta, U. K., Ali, M., Asmat, A., and Baset, A. (2020). COVID-19 Outbreak: Current Scenario of Pakistan. New Microbes New Infect. 35. 100681. doi:10.1016/j.nmni.2020.100681

Weber, W. W. (2015). “Drucker, Peter (1909-2005)," in International Encyclopedia of the Social \& Behavioral Sciences. Second Edition, 662-667. doi:10.1016/B9780-08-097086-8.61190-X

Welter, F., and Gartner, W. B. (2016). A Research Agenda for Entrepreneurship and Context. Lodon, UK: Edward Elgar Publishing. doi:10.4337/9781784716844

Wu, Y., Yuan, C.-H., and Pan, C.-I. (2018). Entrepreneurship Education: an Experimental Study with Information and Communication Technology. Sustainability 10 (3), 691. doi:10.3390/su10030691

Young, M. (2014). What Is a Curriculum and what Can it Do? Curric. J. 25 (1), 7-13. doi:10.1080/09585176.2014.902526

Yousfani, K., Aslam, Y., Mahar, Q., and Kazi, H. (2019). The Impact of Microfinance on Growth of Women Entrepreneurship in Pakistan. J. Entrepreneurship, Business Econ. 7 (1), 133-152.

Yurtkoru, E. S., Acar, P., and Teraman, B. S. (2014). Willingness to Take Risk and Entrepreneurial Intention of university Students: An Empirical Study Comparing Private and State Universities. Proced. - Soc. Behav. Sci. 150, 834-840. doi:10.1016/j.sbspro.2014.09.092

Zollo, L., Laudano, M. C., Ciappei, C., and Zampi, V. (2017). Factors Affecting Universities' Ability to foster Students' Entrepreneurial Behaviour: An Empirical Investigation. J. Manag. Dev. 36 (2), 268-285. https://doi.org/10. 1108/JMD-06-2016-0093

Conflict of Interest: The authors declare that the research was conducted in the absence of any commercial or financial relationships that could be construed as a potential conflict of interest.

Copyright (C) $2021 \mathrm{Li}$, Pervaiz and He. This is an open-access article distributed under the terms of the Creative Commons Attribution License (CC BY). The use, distribution or reproduction in other forums is permitted, provided the original author(s) and the copyright owner(s) are credited and that the original publication in this journal is cited, in accordance with accepted academic practice. No use, distribution or reproduction is permitted which does not comply with these terms. 


\section{APPENDIX: RESEARCH INSTRUMENTS}

\section{Curriculum}

The entrepreneurship course is developed to meet the criteria of the curriculum

The subject of entrepreneurship interests me very much because of interactive learning

I gain a new experience through pursuing the entrepreneurship course

My liking to study entrepreneurship is more compared to other subjects

I can develop entrepreneurship skills through the program

I enjoy learning by doing in the entrepreneurship course

I have a better understanding about business as a result of taking up the entrepreneurship course I like to study entrepreneurship because it teaches real-world situations

The entrepreneurship program taught me to deal with tolerance of ambiguity in the real world

\section{Extracurricular activities}

I have made an effort to become involved in various extracurricular activities

I have extracurricular activities that I have particularly become involved in

Internal locus of control

My life is controlled by others

I can't protect myself against others

My own sections control my life

\section{Entrepreneurial intentions}

Launching a business in my country (Pakistan) is easy

I am sure that my business will be successful

I do my best to run my own business

I have enough knowledge and information to run a new business

I am sure that I can launch a business

I am so eager that launch a business in future

I have tensions and worries about launching this business

I am too eager to run a business I like someday 